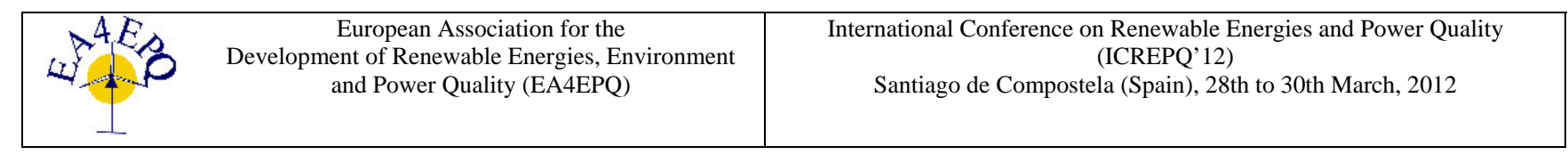

\title{
Development of Bioclimatic Chart for Passive Building Design in Muscat-Oman
}

\author{
N. Al-Azri ${ }^{1}$, Y. Zurigat ${ }^{1}$ and N. Al-Rawahi ${ }^{1}$ \\ ${ }^{1}$ Department of Mechanical and Industrial Engineering \\ Sultan Qaboos University \\ P.O. Box 33 Al-Khoud 123 Muscat, Oman \\ Fax number:+968 2414 1316, e-mail: nalazri@squ.edu.om; zurigat@squ.edu.om; alrawahi@squ.edu.om
}

\begin{abstract}
The selection of building passive thermal design strategies is based heavily on the local climatic conditions. Identifying the best strategy for a given location can be made using bioclimatic charts. Such charts depend on the location atmospheric pressure and are only available at sea level. Moreover, manual usage of these charts is cumbersome and time-consuming. In this paper, the development of a bioclimatic chart for Muscat is described in rigorous details based on Typical Meteorological Year (TMY) data. Muscat bioclimatic chart suggests a hot-humid climate type. December, January, and February are projected on the comfort zone with some slight under-heating where solar heating is sufficient for maintaining comfort. On the other hand, June, and July are the most hot, humid months in the year where mechanical dehumidification and cooling is a must for maintaining thermal comfort. Except for the period from December to February, the humidity tends to be from average to high (above $0.012 \mathrm{~kg} / \mathrm{kg}$ Dry Air, DA). The chart also shows that high thermal mass can be effective during the months of March, April, October, and November. Due to the high humidity, evaporative cooling seems less efficient as a cooling strategy. A generic calculation tool that generates psychrometric chart for any altitude has been developed using MATLAB software.
\end{abstract}

\section{Key words}

Bioclimatic Charts, Passive Cooling, Green Buildings

\section{Introduction}

The comfort zone set by ASHRAE [1] as a general one assumes no consideration to people acclamation to different climates. People living in naturally ventilated unconditioned buildings usually have more tolerance to wide change in the temperature of a summer day [2] . In addition to the geographically-impacted disparity in the perception of comfort, there are other factors that can impact the human sensation of comfort. Macpherson [3] specified six factors that can impact the sensation of comfort which are air speed, mean radiant temperature (MRT), metabolic rate, clothing level in addition to temperature and humidity [3]. He also suggested a range of comfort with nineteen indices each is a function of one or more of the six factors impacting the level of comfort. An even more popular model that takes into consideration the local human factors is the one proposed by Fanger [4]. In addition to the environmental variables, he also considered the activity level and the clothing level. His model was experimentally derived from the responses of college-age subjects set in a uniform environment at steady state conditions. The predictive Mean Vote (PMV) is another model used to express thermal comfort. In this model, Fanger [4] used the result of his experiment to model a graded expression for thermal comfort using sevenpoints-scale qualitatively ranked in the same manner as ASHRAE scale (cold, cool, slightly cool, neutral, slightly warm, warm and hot). However, the quantitative scale ascends from -3 to 3 instead of ASHRAE's scale that goes from 1 to 7 . In this model, the six factors affecting comfort are modeled in a complex equation that quantifies comfort according to the seven grades. The term predicted mean vote implies the predicted mean of votes raised by a large population of people expressing their thermal comfort in a given environment.

Thermal neutrality is another measure of comfort. It is defined as the temperature at which a person feels thermally comfortable, i.e. neutral [5]. Thermal neutrality is modeled using lab and field experiments and found to be highly dependent on the outdoor temperature [5] and is given by:

$T_{\text {neutrality }}=11.9+0.534 T_{\text {outdoor }}$

Another measure that deals with heating and cooling loads in relation to the outdoor conditions is the degree day method. This method can be defined as the annual cumulative time weighted temperature [6]. In this method, a reference indoor temperature is set and the difference between the reference temperature and the mean daily outdoor temperature is calculated for the whole year to give heating degree-days and cooling-degree days. This method 
is very useful when the order of the load is to be compared from one year to another for the same location [6].

In general, the selection of building passive thermal design strategies is based heavily on the local climatic conditions. Identifying suitable strategy for a given location can be made using bioclimatic charts. Olgyay's bioclimatic chart (Fig. 1), developed in the 1950's, was one of the early attempts to specify different zones at different combinations of relative humidity (as abscissa) and dry bulb temperatures (as ordinate).

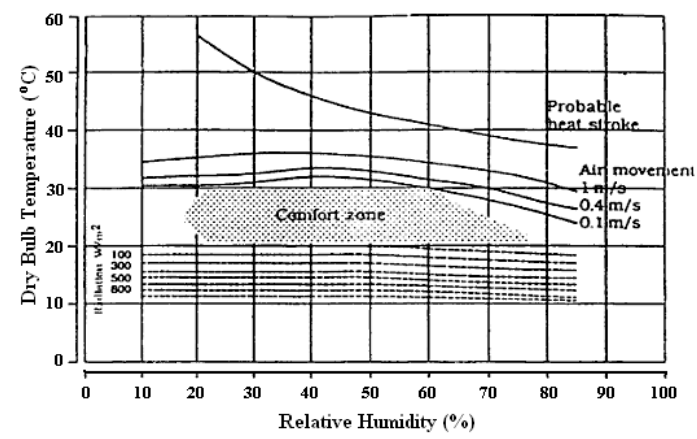

Fig.1. Olgyay’s Bioclimatic Chart [7].

Oglyay's chart has a constant comfort in the range from 20 to $30{ }^{\circ} \mathrm{C}$. The level of comfort is applicable to indoor spaces with the indoor level of clothing. The comfort zone is shown at the center of Olgyay's chart. The chart takes into consideration levels of comfort that can be felt outside the comfort zone but in combination with ranges of other climatic factors such as mean radiant temperature, wind speed and solar radiation. Above the lower boundary of the zone shading is necessary to maintain reasonable level of comfort. Up to $10{ }^{\circ} \mathrm{C}$ below the comfort zone, comfort can be retained provided that there is enough solar radiation to offset the decrease in temperature. Likewise, to retain comfort up to around $10{ }^{\circ} \mathrm{C}$ above the zone, wind speed can offset the increase in temperature. Evaporative cooling according to this chart is another means to retain comfort at high temperature values but low humidity.

Since Olgyay's chart only considers the outdoor conditions disregarding the indoors physiological considerations, it is only applicable for hot humid climates where there is minimal fluctuations between the indoors and the outdoors temperatures [6].

Another more popular bioclimatic chart is that of Givoni [2],[8]. This chart is based on the linear relationship between the temperature amplitude and vapor pressure of the outdoor air. Givoni's chart identifies the suitable cooling technique based on the outdoor climatic condition. Five zones are identified on Givoni's chart: thermal comfort, natural ventilation, high mass, high mass with night ventilation and evaporative cooling.

Bioclimatic charts are utilized by first identifying the average monthly condition. For each month, the average of the daily maximum temperature is calculated and matched with the average of the minimum daily absolute humidity to form the point $\left(\bar{T}_{\max }, \bar{w}_{\min }\right)$. Likewise, the average of the daily minimum temperature is matched with that of the average daily maximum absolute humidity to form $\left(\bar{T}_{\min }\right.$ , $\left.\bar{w}_{\text {max }}\right)$. The placement of the line segment connecting the two points will determine the proper passive cooling strategy for that month.

Givoni's chart (Fig. 2) is mainly applicable to residential and office buildings where heat gain is minimal [9]. Modifications to Givoni's chart that suit nondomestic buildings can also be found in the literature [10]. The natural ventilation zone on Givoni's chart assumes that the indoor mean radiant temperature and the vapor pressure are the same as those at outdoor conditions; an assumption that limits the application to buildings with medium to high thermal structure [9].

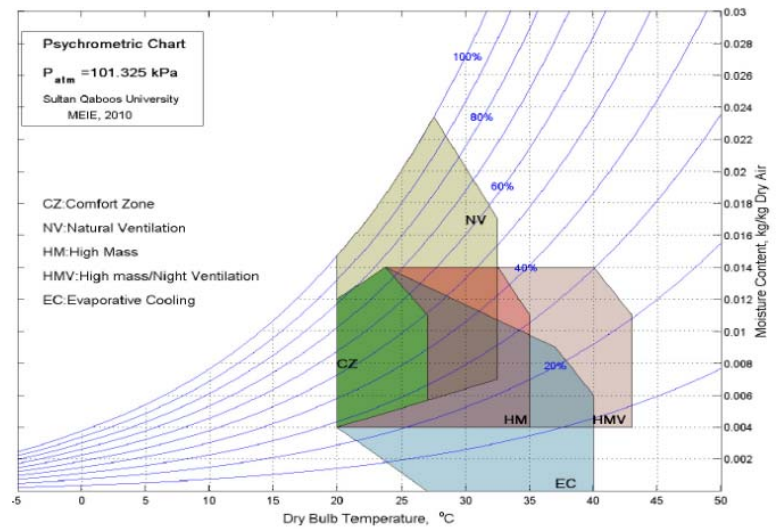

Fig.2. Givoni’s Bbioclimatic Chart Plotted From Givoni’s Chart Data.

At high temperatures, mechanical air-conditioning is necessary to keep a habitable environment. On the left of the comfort zone (CZ), heating is needed to restore comfort using solar heating if the shift is slight but mechanical heating is necessary if the temperature is too low. The high thermal mass effect is provided by heavy construction that helps absorb heat that would be released overnight [11]. If the weather is hot and dry, night ventilation will help releasing heat through windows, assisted by fans if necessary.

Using TMY weather data, bioclimatic chart for Muscat has been developed. The first step in the development of Givoni chart is the development of the background psychrometric chart for local conditions based on psychrometric relations.

\section{Psychrometric Chart Calculations}


Psychrometric charts are very important in many respects. They are very essential for the design and analysis of heating, ventilation and air conditioning (HVAC) systems. These calculations accounts for the relationships interrelating dry and wet bulb temperatures, relative and absolute humilities, enthalpy and specific volume. Psychrometric charts, similar to thermodynamic charts, can also be used for specifying these parameters for a given altitude. These charts are also used for referencing comfort zones for better evaluation of the level of comfort in HVAC system design.

The equations used in the development of the psychrometric chart are based on the proximity of the air-water vapor mixture to ideal gases [12]. In this approximation, the ambient air is treated as a mixture of its two main components: dry air and water vapor. The thermodynamic properties of this mixture can be specified with the knowledge of any two other properties. But due to the high nonlinearity of some of the equations interrelating these parameters, numerical techniques have proved indispensible in psychrometric calculations. The following set of functions is plotted on absolute humidity $\left(\mathrm{w}\right.$ : $\mathrm{kg} \mathrm{H}_{2} \mathrm{O} / \mathrm{kg}$ Dry air) versus dry bulb temperature $\left(T:{ }^{\circ} \mathrm{C}\right)$ domain. The order of these functions is arbitrary as each function is a separate set of points $\mathrm{w}=f(T)$, i.e., each function needs to be expressed either analytically or numerically as $w=f(T)$.

\section{A. The Abscissa (T-Axis)}

Initially, a range of dry temperature values is chosen for the abscissa. At sea level (i.e. $\mathrm{P}=101325 \mathrm{~Pa}$ ), this range is usually selected from -10 to about $55{ }^{\circ} \mathrm{C}$. For each temperature value $\left({ }^{\circ} \mathrm{C}\right)$, the vapor pressure $(\mathrm{Pa})$ of water can be calculated using the correlations:

$$
\begin{gathered}
P^{v}=610.78 \exp \left(\frac{21.874 \mathrm{~T}}{265+0.9615 T}\right) \\
\text { for }\left\{\begin{array}{c}
-40^{\circ} \mathrm{C} \leq T<0^{\circ} \mathrm{C} \\
-40 \mathrm{~kJ} / \mathrm{kg} \leq \mathrm{h}<9.43 \mathrm{~kJ} / \mathrm{kg} \\
12.838 \mathrm{~Pa} \leq P<610.78 \mathrm{~Pa}
\end{array}\right. \\
\text { for }\left\{\begin{array}{c}
P^{v}=610.78 \exp \left(\frac{17.269 T}{237.78+T}\right) \\
0.43 \mathrm{~kJ} / \mathrm{kg} \leq \mathrm{h}<537 \mathrm{~kJ} / \mathrm{kg} \\
610.78 \mathrm{~Pa} \leq P<22870.52 \mathrm{~Pa}
\end{array}\right. \\
P^{v}=610.78 \exp \left(\frac{17.269 T}{236.3+1.01585 T}\right) \\
\text { for }\left\{\begin{array}{c}
0{ }^{0} \mathrm{C} \leq T \leq 110 \\
537 \mathrm{~kJ} / \mathrm{kg} \leq h \\
33870.52 \mathrm{~Pa} \leq P \leq 143292.97 \mathrm{~Pa}
\end{array}\right.
\end{gathered}
$$

The vapor pressure value will be used for the relative humidity curves.
In later steps, these correlations will also be used to find the temperature as a function of the vapor pressure and hence the pressure range is also given. Likewise, the enthalpy range is evaluated in this work at the atmospheric pressure, $101325 \mathrm{~Pa}$. The specification of the enthalpy range will prove very useful when plotting the constant enthalpy lines as will be discussed later.

\section{B. The Ordinate (w-Axis)}

The ordinate of the plot is the absolute humidity, and for the above range of temperature at atmospheric level, it is usually displayed from 0 to $0.03\left(\mathrm{~kg} \mathrm{H}_{2} \mathrm{O} / \mathrm{kg}\right.$ Dry air).

For programmability, all curves and lines including gridlines must be mathematically manipulated and rewritten as absolute humidity being a function of dry bulb temperature. The first curve is the absolute humidity curve at saturation (i.e. $100 \%$ relative humidity). The equation of this curve can be found in the literature [1],[12]:

$W=\frac{0.62198 P^{v}}{P-P^{v}}$

Whereas $\mathrm{w}$ is the absolute humidity (kg moist/kg dry air), $\mathrm{P}^{\mathrm{v}}$ is the vapor pressure $(\mathrm{Pa})$ and $\mathrm{P}$ is the atmospheric pressure (Pa), ( $\mathrm{P}=101,325 \mathrm{~Pa}$ at sea level).

\section{Relative Humidity Curves}

For the rest of the relative humidity curves, the same equation is used with the appropriate proportion of the vapor pressure:

$w=\frac{0.62198 y P^{v}}{P-y P^{v}}$

Whereas $\mathrm{y}$ is the relative humidity coefficient, e.g. for a relative humidity of $50 \%, y=0.5$.

A number of curves are plotted as needed for different values of $\mathrm{y}$, usually from 0.1 to 0.9 in addition to the absolute saturation curve, $y=1.0$.

\section{Vertical Gridlines}

The vertical gridlines are usually stretched from the abscissa to the saturation line. Two points need to be specified for a straight line. To align each gridline with the dry bulb temperature tick mark on the abscissa, these two points are better chosen to be $(T, 0)$ and $\left(T, w_{s}\right)$; whereas $T$ is the given dry bulb temperature tick mark and $\mathrm{w}_{\mathrm{s}}$ is the corresponding absolute humidity for the dry bulb temperature at $100 \%$ relative humidity (the saturation curve). $\mathrm{W}_{\mathrm{s}}$ is directly calculated using Eq.(3), $\mathrm{P}^{\mathrm{v}}$ in this equation is calculated using Eq. (2) for each value of $\mathrm{T}$. 


\section{E. Horizontal Gridlines}

The horizontal gridlines are stretched from the vertical axis to the saturation curve (100\% relative humidity curve). As in the vertical gridlines, two points are needed to plot each gridline. Similar to the vertical gridlines, the two points are $\left(T_{d p}, w\right)$ and $\left(T_{\max }, w\right)$ whereas $T_{d p}$ is the dew point corresponding with each absolute humidity, $\mathrm{w}$ at the tick mark on the ordinate, Tmax is the chosen maximum dry bulb temperature on the abscissa. Hence, we need to find $T_{d p}$ as a function of $\mathrm{w}$.

From Eq. (3), we can solve for $\mathrm{P}^{\mathrm{v}}$ :

$P^{v}=\frac{P w}{0.62198+w}$

Once we have calculated $\mathrm{P}^{\mathrm{v}}$, we calculate $\mathrm{T}$ from Eq. (2). Let's express a generic form of (2) as:

$P^{v}=610.78 \exp \left(\frac{A T}{B+C T}\right)$

Whereas A, B and C are the appropriate constants in (2). T can then be calculated from:

$T=\frac{B \ln \left(\frac{P^{v}}{610.78}\right)}{A-C \ln \left(\frac{P^{v}}{610.78}\right)}$

\section{F. The Specific Volume Curves}

Since the constant specific volume curves are linear, determining two points will suffice for plotting each curve. These curves start at the abscissa (from point $\left(T_{0}, 0\right)$ at which the absolute humidity is zero) and end at the saturation curve, $\left(T_{s}, w_{s}\right)$, hence in this step we need to determine $T_{0}, T_{s}$ and $\mathrm{w}_{\mathrm{s}}$.

The range of constant volume curves should be chosen in accordance with the atmospheric pressure values, a trial run can be used before deciding. For an atmospheric pressure of $101,325 \mathrm{~Pa}$, the constant specific volume curves can be chosen from 0.75 to $0.95 \mathrm{~m}^{3} / \mathrm{kg}$ dry air.

The specific volume ( $\mathrm{m}^{3} / \mathrm{kg}$ dry air) is given in the literature by the following equation [12]:

$v=\frac{287.05(T+273.16)}{P-P^{v}}$

For each constant specific volume line (v), we need to determine $\mathrm{T}_{0}, \mathrm{~T}_{\mathrm{s}}$ and $\mathrm{w}_{\mathrm{s}}$, as follows:

a. For each $v$ value, calculate the dry bulb temperature $\left(T_{s}\right)$ at which the line intercepts the saturation curve. For a given atmospheric pressure (P), Eq. (7) is only a function of temperature, since $\mathrm{P}^{\mathrm{v}}$ is itself a function of temperature. Hence, $T_{s}$ is found using a numerical method such as
Newton-Raphson equation, in which the iterative equation will be:

$T_{s(i+1)}=T_{s(i)}-\frac{f\left(T_{s(i)}\right)}{f^{\prime}\left(T_{s(i)}\right)}$

whereas

$$
f\left(T_{s(i)}\right)=v-\frac{287.05\left(T_{s(i)}+273.16\right)}{P-P^{v}\left(T_{s(i)}\right)}
$$

and $f^{\prime}\left(T_{s(i)}\right)$ is the derivative of this equation with respect to $\mathrm{T}$.

b. Having found $T_{s}, w_{s}$ can be calculated directly by substituting $\mathrm{T}_{\mathrm{s}}$ to calculate $\mathrm{P}^{\mathrm{v}}$ using Eq. (2), and then $\mathrm{w}_{\mathrm{s}}$ using Eq.(3).

c. $\mathrm{T}_{0}$ is the dry bulb temperature $\left({ }^{\circ} \mathrm{C}\right)$ at zero absolute humidity (absence of moist). So we can use the ideal gas equation which is equivalent to Eq. (7) with $\mathrm{P}^{\mathrm{v}}=0$ :

$$
T_{0}=\frac{P v}{287.05}-273.16
$$

\section{G. The Enthalpy Lines}

Likewise, constant enthalpy curves are straight lines with a negative slope which covers the whole plot area and have a diagonal axis. The presentation of these lines is the trickiest part.

The enthalpy is calculated as a function of temperature and absolute humidity using the equation:

$h=1.006 T+w(2501+1.77 T)$

The enthalpy ( $\mathrm{kJ} / \mathrm{kg}$ Dry Air)) lines in addition to the diagonal axis are displayed in two steps:

a. The line segment from the abscissa to the saturation curve: To plot this segment we need to specify two points $\left(T_{0}, 0\right)$ at the abscissa and $\left(T_{s}, w_{s}\right)$ at the saturation line; hence for a given constant enthalpy h (kJ/kg dry air) we need to determine $T_{s}, w_{s}$ and $T_{0}$.

$T_{s}$ is calculated from (10) using a numerical method such as Newton-Raphson method. At saturation, the absolute humidity (w) in (10) is a function of vapor pressure which in turn is a function of T. Hence, (10) can be rewritten as a function of $(\mathrm{T})$ :

$g(T)=1.006 T+\frac{379.8929 \exp \left(\frac{A T}{B+C T}\right)}{P-610.78 \exp \left(\frac{A T}{B+C T}\right)}(2501+$

$1.77 T)-h$

Using Newton-Raphson numerical method, the root of this equation is $T_{s}$ at the given value of $h$. The selection of the 
constants $\mathrm{A}, \mathrm{B}$ and $\mathrm{C}$ is based on the $\mathrm{h}$ value according to the appropriate $h$ range given in (2).

Newton-Raphson iterative equation is:

$T_{(i+1)}=T_{(i)}-\frac{g\left(T_{(i)}\right)}{g^{\prime}\left(T_{(i)}\right)}$

Due to the complexity of $g(T)$, its first derivative can be evaluated by using a numerical method. Using a central finite difference with a step size $\delta$ :

$g^{\prime}(T) \cong \frac{g(T+\delta)-g(T-\delta)}{2 \delta}$

and hence, (12) can be rewritten as:

$T_{(i+1)}=T_{(i)}-\frac{2 \delta \times g\left(T_{(i)}\right)}{g\left(T_{(i)}+\delta\right)-g\left(T_{(i)}-\delta\right)}$

A value of $\delta=0.005$ should lead to rapid convergence.

Having obtained $T_{s}$, the calculation of $\mathrm{w}_{\mathrm{s}}$ directly follows by calculating $\mathrm{P}^{\mathrm{v}}$ from (2) and then $\mathrm{w}_{\mathrm{s}}$ from (3). On the other hand, $\mathrm{T}_{0}$ is the dry bulb temperature at which the constant enthalpy line intercepts the abscissa i.e. the absolute humidity is zero. Using (10) with $\mathrm{w}=0$ :

$T_{0}=\frac{h}{1.006}$

b. In order to add the enthalpy diagonal axis, the constant enthalpy lines are extended by a length $\Delta$ beyond the saturation line. $\Delta$ is chosen arbitrarily in a way that enhance the readability of the chart. The additional segment of each of the enthalpy lines will require two points. One point is of course $\left(T_{s}, w_{s}\right)$ while the other point can easily be located using basic geometry.

For the iterative numerical methods discussed above, any reasonable temperature value $\left(20{ }^{\circ} \mathrm{C}\right.$ used here) can be used as an initial guess. Plot-producing solver, the Matlab, is used to develop a code for generating a psychrometric chart. Fig. 3 shows the one developed at sea level.

\section{Comfort Zone on Psychrometric Charts}

The thermal comfort zone depends on different factors such as environment, type of activity and type of clothing. In addition, there are some relative factors such as nonuniformity of environment, age, gender and outdoor climate [1] . ASHRAE thermal sensation scale has seven grades: hot, warm, slightly warm, neutral, slightly cool, cool and cold with each grade assigned a numerical value, from +3 to -3 , in respective order. The comfort zones as specified by
ASHRAE is the zone where $80 \%$ of sedentary or slightly active people find the environment thermally comfortable [1].

The level of comfort can change considerably with the level of clothing and hence ASHRAE defines the comfort zone for two levels of clothing $0.5 \mathrm{col}\left(0.44 \mathrm{ft}^{2} .{ }^{2} .{ }^{0} \mathrm{~F} / \mathrm{Btu}\right)$, shortsleeved shirt and pants, and $1.0 \mathrm{col}\left(0.88 \mathrm{ft}^{2} . \mathrm{h}^{\circ}{ }^{\circ} \mathrm{F} / \mathrm{Btu}\right)$, winter business suit. There is no lower humidity specification set by ASHRAE while the maximum is not to exceed absolute humidity of $0.012 \mathrm{~kg} / \mathrm{kg}$ dry air, as shown on Fig. 3.

At the center of each zone, a normal person will feel thermally comfortable (neutral sensation) if he or she has the designated clothing level. As this person shifts towards the boundaries of these zones, the sensation changes by about +0.5 on ASHARE scale in the warmer zone and by -0.5 in the colder zone [1].

These zones are for the above-mentioned clothing level with air speed less than $0.2 \mathrm{~m} / \mathrm{s}$ and at a sedentary activity. With the change of these stipulations, the temperature boundary decreases by about $0.56{ }^{\circ} \mathrm{C}$ with clothing level increasing by 0.1 clo. The zone temperature can also be decreased by 1.4 ${ }^{\circ} \mathrm{C}$ when the activity increases by 1.2 met [1].

The distribution of the hourly climatic data can be better evaluated on a psychrometric chart with reference to a comfort zone. Fig. 3 shows the distribution of hourly dry bulb temperature and absolute humidity in Muscat.

\section{Bioclimatic Chart Development and Analysis}

Table 1 shows the mean dry -bulb temperature and the mean absolute humidity for each month in Muscat along with the neutrality temperature according to Humphrey [5]. The mean values are the average of the hourly readings per month and so they might be very slightly (around 2\%) different from the average of the average minimum and maximum values shown on Table 1 . Muscat is generally humid and hot in the summer and moderate in the winter.

Table 1 shows the average values of daily maximum and minimum readings for each month. These values are used to determine the proper passive cooling strategy to be used as shown on Givoni's bioclimatic chart (Fig. 2).

From the bioclimatic chart (Fig. 4), the collection of the average monthly points suggests a hot-humid climate type. December, January and February are projected on the comfort zone with some slight under-heating where solar heating is sufficient for maintaining comfort. 


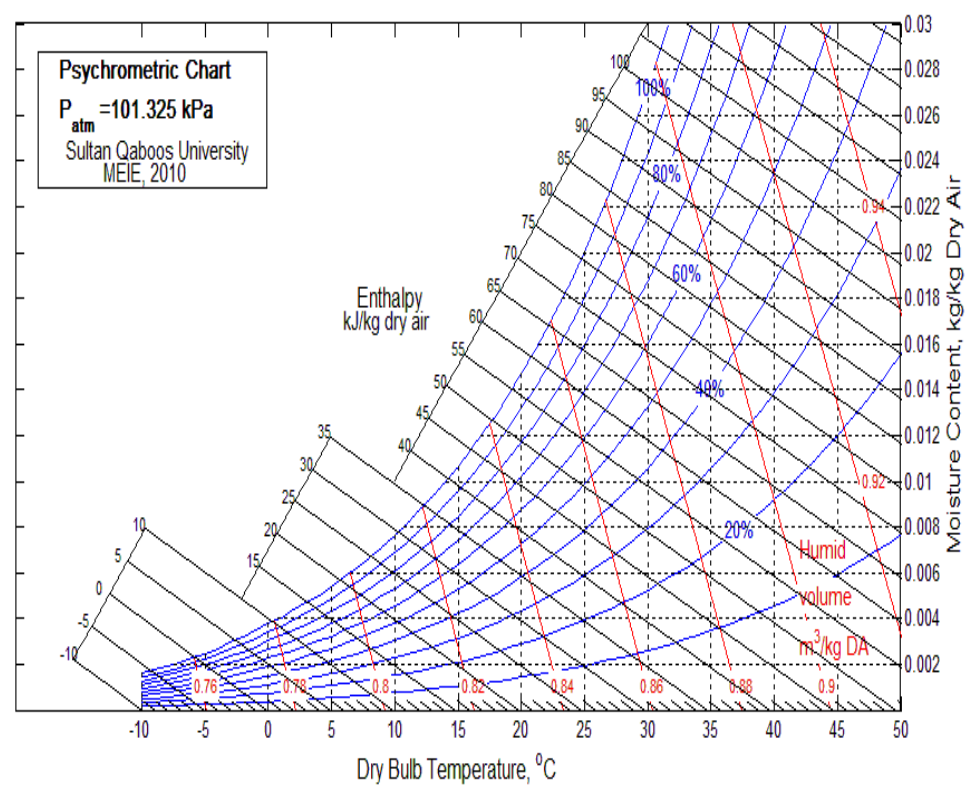

Fig. 3. The Psychrometric Chart at Sea Level Generated with Matlab with the Hourly Dry Bulb Temperature and Absolute Humidity for Muscat, Oman and the ASHRAE Comfort Zones for $1.0 \mathrm{col}$ and $0.5 \mathrm{col}$ Clothing Levels.

Table 1. Average Maximum and Minimum Temperatures and Absolute Humidifies, and the Overall Average Monthly Temperature and Absolute Humidity In Muscat, Oman.

\begin{tabular}{|c|c|c|c|c|c|c|c|}
\hline Month & $\bar{T}_{d b, \max }$ & $\bar{T}_{d b, \min }$ & $\bar{w}_{\max }$ & $\bar{w}_{\text {min }}$ & $T_{d b, \text { mean }}$ & $w_{\text {mean }}$ & $T_{\text {neutrality }}$ \\
\hline Jan & 25.4 & 16.7 & 0.0110 & 0.0071 & 21.4 & 0.0089 & 23.3 \\
Feb & 25.9 & 17.8 & 0.0121 & 0.0074 & 22.0 & 0.0100 & 23.7 \\
Mar & 28.7 & 20.2 & 0.0148 & 0.0084 & 24.4 & 0.0115 & 24.9 \\
\hline Apr & 35.3 & 26.9 & 0.0156 & 0.0079 & 30.9 & 0.0114 & 28.4 \\
May & 38.4 & 29.7 & 0.0199 & 0.0092 & 33.9 & 0.0145 & 30.0 \\
Jun & 40.0 & 30.9 & 0.0224 & 0.0100 & 35.2 & 0.0163 & 30.7 \\
\hline Jul & 39.0 & 30.5 & 0.0233 & 0.0118 & 34.6 & 0.0177 & 30.4 \\
Aug & 33.5 & 27.1 & 0.0217 & 0.0162 & 29.9 & 0.0195 & 27.9 \\
Sep & 35.6 & 26.7 & 0.0213 & 0.0127 & 30.9 & 0.0174 & 28.4 \\
\hline Oct & 35.0 & 25.8 & 0.0186 & 0.0096 & 29.9 & 0.0143 & 27.8 \\
Nov & 30.4 & 22.6 & 0.0157 & 0.0094 & 26.4 & 0.0124 & 26.0 \\
Dec & 25.2 & 17.7 & 0.0115 & 0.0081 & 21.5 & 0.0098 & 23.4 \\
\hline
\end{tabular}

On the other hand, June and July are the most hot, humid months in the year where mechanical dehumidification and cooling is a must for maintaining thermal comfort. Except for the period from December to February, the humidity tends to be from average to high (above 0.012 $\mathrm{kg} / \mathrm{kg}$ DA). Whether practical or not, the chart shows that high thermal mass can be effective during the months of March, April, October and November. Due to the high humidity, evaporative cooling seems less efficient a cooling strategy.

\section{Conclusion}

In this paper a bioclimatic chart for Muscat, Oman has been developed. A detailed step-by-step formulation and procedure for the development of such chart is described and different passive design strategies for Muscat have been evaluated. The chart is based on Muscat Typical Meteorological Year (TMY) data. Based on the chart, Muscat is identified as of hot-humid climate type. December, January and February are projected on the 


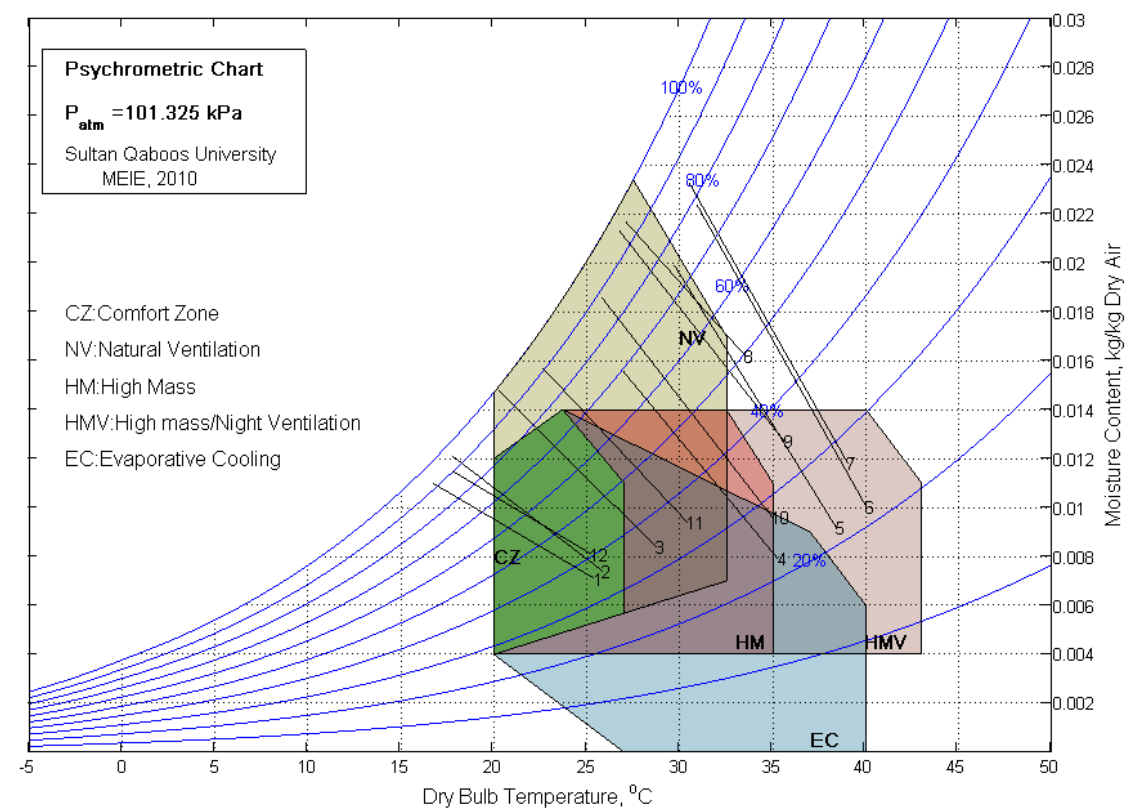

Fig. 4. Givoni’s Bioclimatic Chart for Muscat, Oman.

comfort zone with some slight under-heating where solar heating is sufficient for maintaining comfort. On the other hand, June and July are the most hot, humid months in the year where mechanical dehumidification and cooling is a must for maintaining thermal comfort. Except for the period from December to February, the humidity tends to be from average to high (above 0.012 $\mathrm{kg} / \mathrm{kg}$ DA). The chart also shows that high thermal mass can be effective during the months of March, April, October and November. Due to the high humidity, evaporative cooling seems less efficient a cooling strategy. A general calculation tool that generates psychrometric chart for any altitude has been developed using MATLAB software. Also, the bioclimatic chart is generated by this software at a press of a button. Using this tool, it is a matter of minutes to generate a bioclimatic chart for any location in Oman for which weather hourly data are available.

\section{Acknowledgments}

The Research leading to these results has received Research Project Funding from the Research Council of the Sultanate of Oman Research Agreement No [CR SQU 010001 ]

\section{References}

[1] ASHRAE, 2009, ASHRAE Handbook Fundementals, Atlanta, GA: ASHRAE.

[2] Givoni, B.,1992, Comfort, climate analysis and building design guidelines. Energy and Buildings 1:11-23.
[3] MacPherson, R.K.,1973, Thermal stress and thermal comfort. Ergonomics 16:1366-5847.

[4] Fanger, P.O., 1972, Thermal Comfort: Analysis and Applications in Environmental Engineering, New Yourk: McGraw-Hill.

[5] Humphreys, M.A.,1978, Outdoor temperature and comfort indoor. Building Research and Practice 6: 92-105.

[6] Sayigh, A. and A. H. Marafia, 1998,Thermal comfort and the development of bioclimatic concept in building design. Renewable and Sustainable Energy Reviews 2: 324.

[7] Olgyay, V., 1963, Design with Climate, Bioclimatic Approach and Architectural Regonalism, New Jersey: Princeton University Press.

[8] Givoni, B.,1994, Passive and Low Energy Cooling of Buildings. New Yourk: Van Nostrand Reinhold.

[9] Watson, D., 1981, Analysis of weather data for determinimg appropriate climate control strategies in archetectural design, In The International Passive and Hybrid Cooling Conference, edited by R. Haisley, Miami Beach: Solar Energy Association.

[10] Lomas, K. J., D. Fiala, M. J. Cook, P. C. Copper, 1994, Building bioclimatic charts for non-domestic buildings and passive downdraught evaporative cooling, Building and Environment 39: 661-676.

[11] Szokolay, S.V., 2004, Introduction to Architectural Science: The Basis of Sustainable Design, Architectural Press: Oxford.

[12] Singh, A. K., H. Singh, S. P. Singh, and R. L. Sawhney, 2002, Numerical calculation of psychrometric properties on a calculator. Building and Environment 37: 415-419. 